\title{
Pseudomonas aeruginosa blepharitis in a patient with vancomycin induced neutropenia
}

\author{
Michael A JOHN MB ChB FRCPC, ThOMAS W AUSTIN MD FRCPC, ANNE MARIE BOMBASSARO PharmD
}

\begin{abstract}
MA JOHN, TW AUSTIN, AM BOMBASSARO. Pseudomonas aeruginosa blepharitis in a patient with vancomycin induced neutropenia. Can J Infect Dis 1996;7(1):63-65. A patient who developed a necrotizing pseudomonas blepharitis as a complication of drug induced neutropenia is reported. Although the patient's neutrophil count recovered and he survived his infection, radical reconstructive surgery of his eyelids was required. Clinicians should keep in mind that in patients with predisposing risk factors, even commonly encountered infections such as blepharoconjunctivitis may be caused by atypical pathogens.
\end{abstract}

Key Words: Blepharitis, Neutropenia, Pseudomonas aeruginosa, Vancomycin

\section{Blépharite à Pseudomonas aeruginosa chez un patient atteint de neutropénie induite par la vancomycine}

RÉSUMÉ : Un patient qui a développé une blépharite nécrosante à Pseudomonas consécutive à une neutropénie d'origine médicamenteuse est décrit ici. Bien que la numération des neutrophiles chez ce patient soit revenue à la normale et qu'il ait survécu à l'infection, il a fallu procéder à une reconstruction chirurgicale de ses paupières. Les cliniciens doivent garder à l'esprit que chez les patients qui présentent des facteurs de risque, les infections mêmes courantes, comme la blépharoconjonctivite, peuvent être causées par des organismes pathogènes atypiques.

$\mathrm{B}$ acteria are the principal pathogens responsible for most infections of the eyelids, with skin flora organisms such as Staphylococcus or Streptococcus species being the most common cause $(1,2)$. We present a patient who developed pseudomonal blepharitis during an episode of drug induced neutropenia.

\section{CASE PRESENTATION}

A 62-year-old male was admitted to his local hospital on July 26, 1991 for management of exfoliative dermatitis. In hospital the dermatitis was managed with oral prednisone 40 $\mathrm{mg}$ daily, which was tapered to $20 \mathrm{mg}$ over three weeks. On August 19 the patient was started on vancomycin $1 \mathrm{~g}$ intravenously every $12 \mathrm{~h}$ because of fever and a blood culture positive for Staphylococcus epidermidis. White blood cell count at that time was $10 \times 10^{9} / \mathrm{L}\left(7.9 \times 10^{9} / \mathrm{L}\right.$ neutrophils $)$. Nine days later a repeat blood culture again grew $\mathrm{S}$ epidermidis and the patient remained febrile despite vancomycin therapy.

On August 28 he was transferred to Victoria Hospital for management of suspected infection unresponsive to therapy. On examination, vital signs were stable, temperature was $38.7^{\circ} \mathrm{C}$ and there was generalized exfoliation of the skin with

Department of Medical Microbiology, University Hospital; Infectious Diseases and Clinical Pharmacy Services, Victoria Hospital; and Faculty of Medicine, University of Western Ontario, London, Ontario

Correspondence and reprints: Anne Marie Bombassaro, Pharmacy Department, Victoria Hospital, 800 Commissioners Road East, London, Ontario N6A 4G5. Telephone 519-685-8235, fax 519-685-8304

Received for publication December 9, 1994. Accepted May 18, 1995 


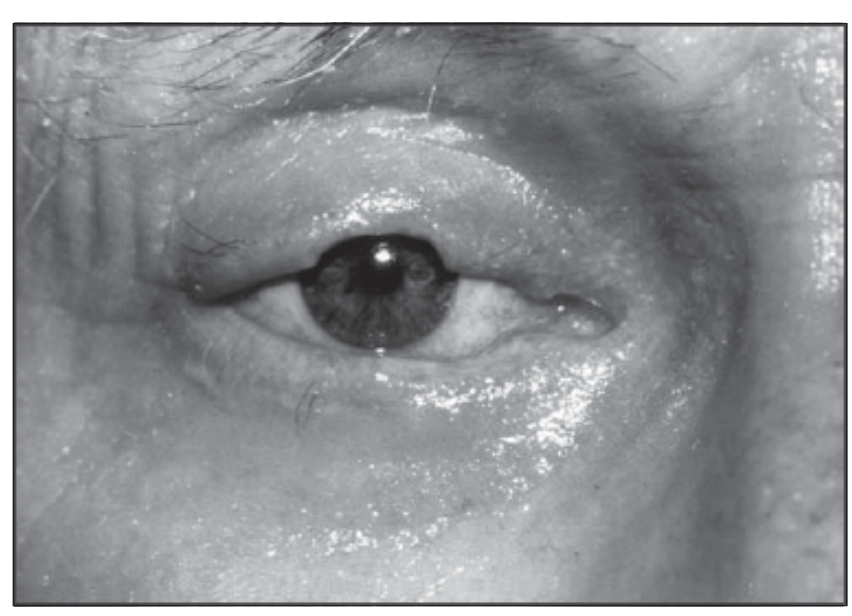

Figure 1) Patient following resolution of neutropenia and Pseudomonas aeruginosa infection. Partial destruction of tarsal plate can be seen

minimal mucositis. Vancomycin was discontinued because differing antibiotic sensitivity patterns of the blood culture isolates suggested these were contaminants and there was no other obvious focus of infection. It was felt that the patient's fever was most likely explained by the exfoliative dermatitis. The total leukocyte count on admission was $2.8 \times 10^{9} / \mathrm{L}$ $\left(0.3 \times 10^{9} / \mathrm{L}\right.$ neutrophils).

On August 30 topical gentamicin was started for a reddened left eye. The following day bilateral blepharitis was noted and systemic cloxacillin therapy started. By September 1 the leukocyte count had fallen to $1.7 \times 10^{9} / \mathrm{L}\left(0.1 \times 10^{9} / \mathrm{L}\right.$ neutrophils) and marked progression of the blepharitis had occurred. The eyelids were swollen and draining purulent discharge with numerous microabscesses present in the meibomian glands of the upper and lower lids. Results of culture of both eyelids showed a light growth of Pseudomonas aeruginosa, sensitive to gentamicin, tobramycin, piperacillin, ceftazidime and ciprofloxacin.

Cloxacillin therapy was discontinued and a 10-day course of parenteral piperacillin and tobramycin was administered, followed by seven days of oral ciprofloxacin. After $48 \mathrm{~h}$ of parenteral therapy, soft tissue swelling on both lids had decreased and no further abscesses appeared. On September 4 several black necrotic areas were noted at the lid margins. Despite a good response to systemic antibiotic therapy and resolution of the neutropenia the patient was left with extensive scarring and tissue loss of both eyelids, which subsequently required reconstructive surgery (Figure 1).

\section{DISCUSSION}

Exfoliative dermatitis may be associated with fever (3) and with an increased risk of cellulitis and septicemia. The interpretation of an elevated temperature in such a patient can be difficult. We believe this patient's initial fever was likely due to his exfoliative dermatitis. However, at the time it was judged that he was septicemic with a coagulase-negative staphylococcus, and vancomycin treatment was commenced. Therapy with vancomycin is reported to cause neutropenia, defined as a polymorphonuclear count of less than $1 \times 10^{9} / \mathrm{L}$ in up to $2 \%$ of patients (4). On admission to our hospital, nine days after commencing vancomycin therapy, the patient had a total white cell count of $3 \times 10^{9} / \mathrm{L}$ and almost no neutrophils. His blepharitis was initially noted on the fifth day of neutropenia.

Blepharoconjunctivitis is commonly observed in individuals who suffer from dry skin or seborrheic dermatitis. Secondary bacterial infection often occurs, usually due to skin flora pathogens such as S aureus or Streptococcus species (2). Our patient's infection was due to $P$ aeruginosa, a well recognized pathogen in the neutropenic host (5), but rarely implicated as a cause of blepharitis (6). A MEDLINE search of the English-language literature revealed only five case reports of blepharitis due to $P$ aeruginosa (2,7-10). As with our case, four of the five patients discussed in these reports had concurrent leukopenia and/or neutropenia. The fifth patient was believed to have been infected iatrogenically via contaminated shampoo that was being applied to the eyelids for prevention of recurrent blepharoconjunctivitis (2). In the majority of the reported cases the infection progressed rapidly over a period of $24 \mathrm{~h}$. Eyelid erythema, swelling and purulent discharge were common presenting signs $(2,7,8,10)$. Subsequent acute necrosis of lid margin(s) and tissue loss occurred in all patients with neutropenia (7-10). Interestingly, the lesions in our patient, and those described previously, resembled ecthyma gangrenosum, a lesion classically associated with $\mathrm{P}$ aeruginosa infections complicating neutropenia $(5,7)$. In the case of a 40-day-old infant with pancytopenia, the necrotizing pseudomonas infection resulted in the destruction of the whole lid apparatus, lacrimal system and corneal perforation due to exposure keratitis (9).

Disruption of the skin barrier due to exfoliative dermatitis and steroid therapy $(11,12)$ used to manage the dermatitis were both likely contributory to the development of infection in our patient. However, we feel that the concomitant drug induced neutropenia was the critical factor. Although our patient's neutrophil count recovered within several days of discontinuing vancomycin therapy and he survived Gramnegative infection, radical reconstructive surgery of his eyelids was required.

Clinicians should be aware that in the presence of predisposing risk factors a common infection such as blepharitis can be caused by infrequently implicated bacteria. The rapid progression of pseudomonal blepharitis and the potential for extensive tissue loss support the need for heightened awareness.

\section{REFERENCES}

1. Smolin G, Okumoto M. Staphylococcal blepharitis. Arch Ophthalmol 1977;95:812-6.

2. Brook I, Hulburd CS. Pseudomonas aeruginosa iatrogenic blepharoconjunctivitis. Arch Ophthalmol 1993;111:26-7.

3. Davies MG, Kersey PJW. Acute hepatitis and exfoliative dermatitis associated with minocycline. BMJ 1989;298:1523-4.

4. Farber BF, Moellering RC. Retrospective study of the toxicity of preparations of vancomycin from 1974 to 1981 . Antimicrob Agents Chemother 1983;23:138-41.

5. Meunier F. Infections in patients with acute leukemia and lymphoma. In: Mandell GL, Bennett JE, Dolin R, eds. Principles and Practice of Infectious Diseases, 4th edn. New York: Churchill Livingstone, 1995:2675-86. 
6. O'Brien TP, Green WR. Periocular infections. In: Mandell GL, Bennett JE, Dolin R, eds. Principles and Practice of Infectious Diseases, 4th edn. New York: Churchill Livingstone, 1995:1129-36.

7. Rosenoff SH, Wolf ML, Chabner BA. Pseudomonas blepharoconjunctivitis: a complication of combination chemotherapy. Arch Ophthalmol 1974;91:490-1.

8. Treister G, Frankl O, Cohen S, Stein R. Metastatic gangrene of the lid in pseudomonas septicemia. Ann Ophthalmol 1975;7:639-41.

9. Steinkoehler FJ, Huber-Spitzy V. Necrotizing destruction of the ocular adnexa by Pseudomonas aeruginosa. J Craniomaxillofac Surg 1988;16:28-30.

10. Prendiville KJ, Bath PE. Lateral cantholysis and eyelid necrosis secondary to Pseudomonas aeruginosa. Ann Ophthalmol 1988;20:193-5.

11. Fauci AS, Dale DC, Balow JE. Glucocorticosteroid therapy: mechanisms of action and clinical considerations. Ann Intern Med 1976;84:304-15.

12. West PM, Flanigan T, Salata RA, Shlaes DM, Katzman M, Lederman MM. Serious infectious complications of corticosteroid therapy for COPD. Chest 1989;95:1180-4. 


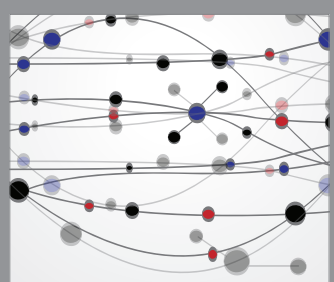

The Scientific World Journal
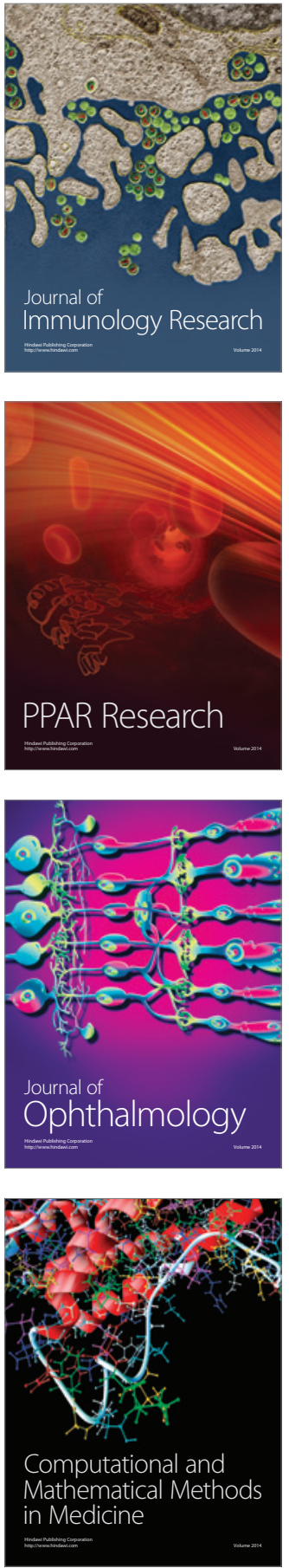

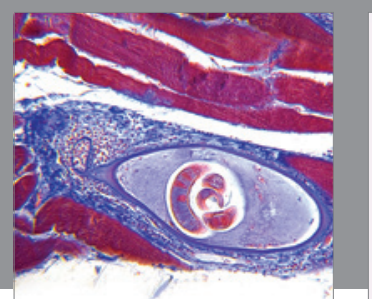

Gastroenterology Research and Practice

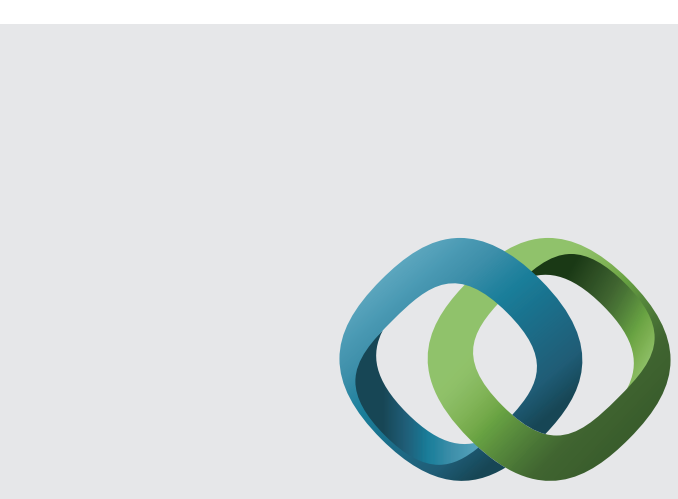

\section{Hindawi}

Submit your manuscripts at

http://www.hindawi.com
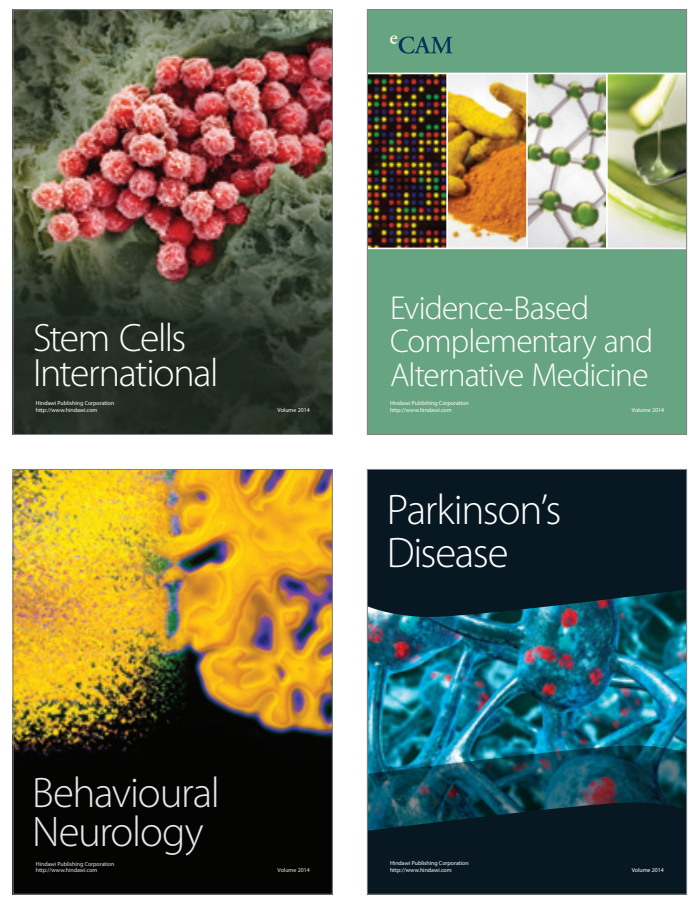
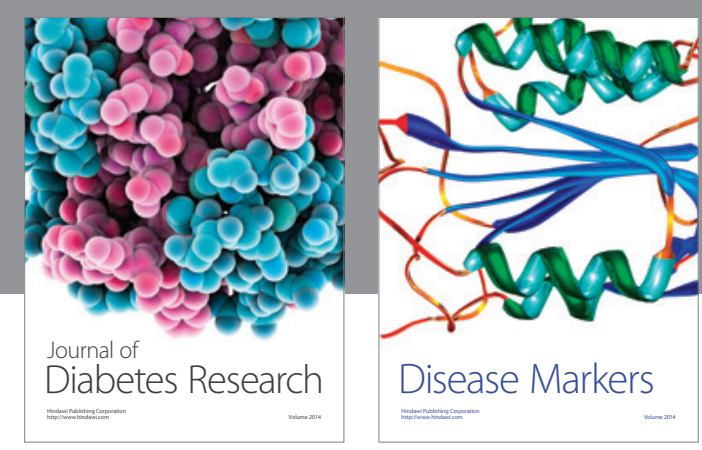

Disease Markers
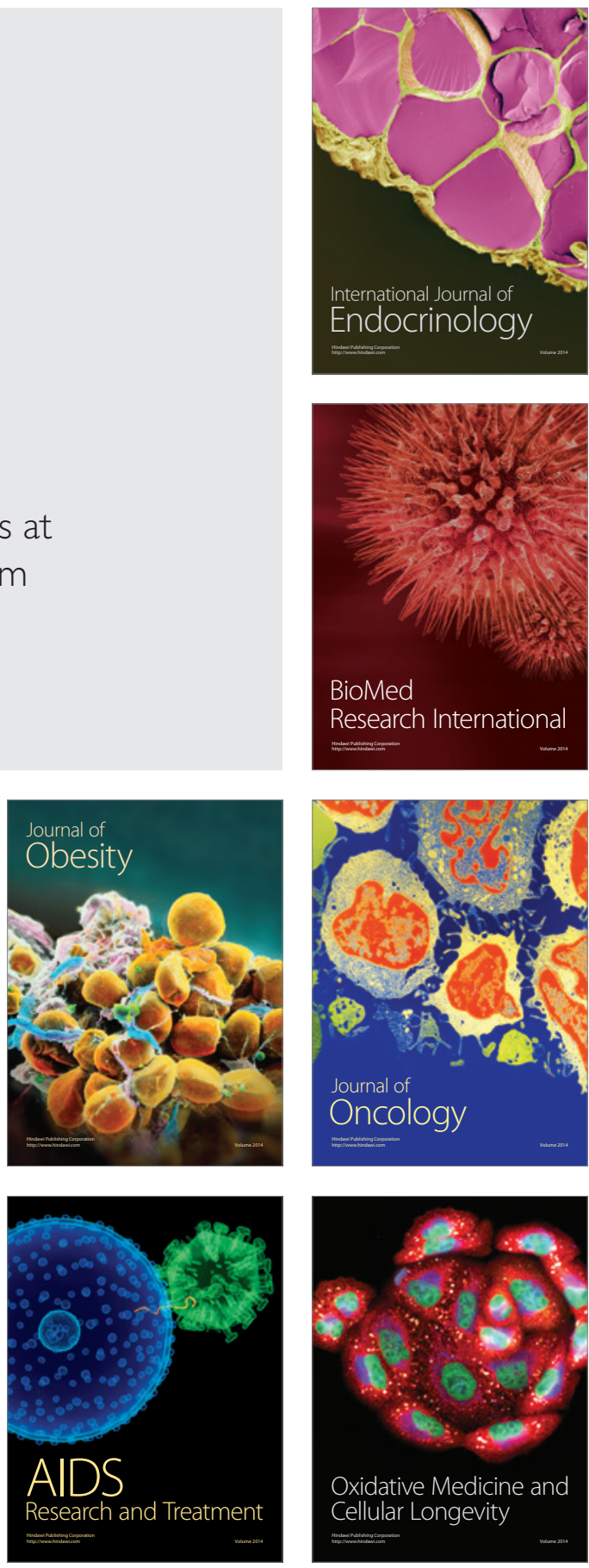